\title{
Use of OTC-drugs prior to Hospitalization
}

\author{
Magnus Pedersen*, Mikkel Brabrand \\ From Proceedings of the 5th Danish Emergency Medicine Conference \\ Aarhus, Denmark. 18-19 April 2013
}

\section{Background}

Use of over the counter (OTC)-drugs is increasing and as it is poorly registered, this can lead to complications. The most commonly used OTC-drugs are analgesics and use is highest among elderly. Our study investigates the use of OTC-drugs 24 hours prior to hospitalization as well as the effect of the drugs.

\section{Methods}

The junior physicians on call interviewed all patients admitted to the medical admission unit at Sydvestjysk Sygehus in Esbjerg on the use of OTC-drugs, using a modified chart template designed for the purpose. All adult patients aged 15 and older admitted over a two week period in August 2012 were included. The patients were asked about the drugs taken, dosage, indication and effect. OTC-drugs where categorised based on ATC-codes.

\section{Results}

From a total of 349 admissions 188 usable chart templates were registered (54\%) and information on OTC usage was registered on 165 of these (88\%). The patients were elderly (median: 70 years) and 43 reported an intake of OTC-drugs (26\%). A total of 22 different OTC-drugs had been consumed with analgesics being the most widely used (74\%). The majority of patients had taken the drugs on a relevant indication (88\%), the most common indication being pain. Half the patients had taken the drugs in a relevant dosage (51\%). Sixty percent felt an effect of the intake and the majority on pain symptoms.

\footnotetext{
* Correspondence: magnuspedersen84@gmail.com Sydvestjysk Sygehus, Esbjerg, Denmark
}

(c) 2013 Pedersen and Brabrand; licensee BioMed Central Ltd. This is an Open Access article distributed under the terms of the Creative Commons Attribution License (http://creativecommons.org/licenses/by/2.0), which permits unrestricted use, distribution, and reproduction in any medium, provided the original work is properly cited. and take full advantage of:

- Convenient online submission

- Thorough peer review

- No space constraints or color figure charges

- Immediate publication on acceptance

- Inclusion in PubMed, CAS, Scopus and Google Scholar

- Research which is freely available for redistribution 